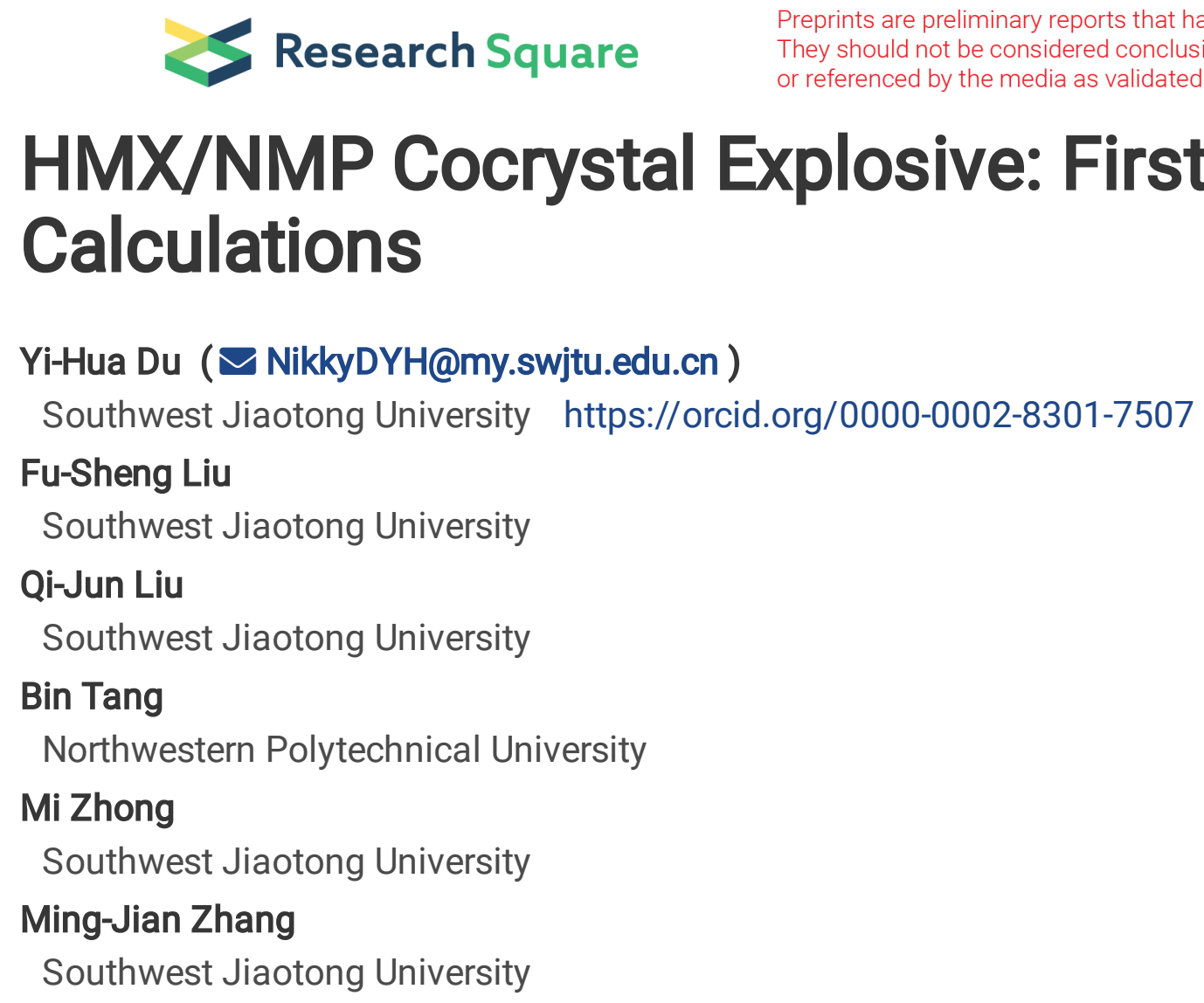

\section{Yi-Hua Du ( $\approx$ NikkyDYH@my.swjtu.edu.cn )}

Southwest Jiaotong University https://orcid.org/0000-0002-8301-7507

Fu-Sheng Liu

Southwest Jiaotong University

\section{Qi-Jun Liu}

Southwest Jiaotong University

\section{Bin Tang}

Northwestern Polytechnical University

\section{Mi Zhong}

Southwest Jiaotong University

\section{Ming-Jian Zhang}

Southwest Jiaotong University

\title{
HMX/NMP Cocrystal Explosive: First-Principles Calculations
}

\section{Research Article}

Keywords: First-principles calculations, HMX/NMP, Electronic properties, Intermolecular interactions

Posted Date: May 4th, 2021

DOl: https://doi.org/10.21203/rs.3.rs-427822/v1

License: (c) (i) This work is licensed under a Creative Commons Attribution 4.0 International License. Read Full License

Version of Record: A version of this preprint was published at Journal of Molecular Modeling on August 18th, 2021. See the published version at https://doi.org/10.1007/s00894-021-04879-x. 


\section{Abstract}

The band structure, total density of states and atomic orbit projected density of states analysis were performed to investigate HMX/NMP cocrystal by using the first-principles calculations. Results show that the HMX/NMP cocrystal is equipped with a direct band gap and the interactions between HMX and NMP molecules are rather weak. The $\mathrm{O}$ orbits hybridize with $\mathrm{H}$ orbits and the parts of charge transform from $\mathrm{H}$ to $O$ atoms by analyzing the DOS. The HMX/NMP cocrystal possesses three types of intermolecular interactions between $\mathrm{HMX}$ and NMP, these interactions and the arrangement of two molecules in the structure are the main reasons for the low sensitivity of the cocrystal. The $\mathrm{C}-\mathrm{H}$...O type hydrogen bond is the key role in forming the structure, and the strength of the hydrogen bond interaction for $\mathrm{C}-\mathrm{H}$... O-N is higher than that of $\mathrm{C}-\mathrm{H}$...O-C.

\section{Introduction}

Energetic materials usually refer to organic compounds containing energy-containing groups (such as nitro, amino and azide groups) in molecules, which release significant quantities of energy in an instant when there is a chemical reaction [1-4]. Energetic materials have a wide range of applications, for example, their chemical energy can be used to do work for missile launch and can be used as gas generators [5]. Explosives, propellants and pyrotechnics are common energetic materials, which are widely used in civil and military fields [6-8]. A great deal of research has been done on energetic materials, such as 2,4,6-trinitrotoluene (TNT), hexahydro-1,3,5-trinitro-1,3,5-triazine (RDX) and octahydro1,3,5,7-tetranitro-1,3,5,7-tetrazocine (HMX) [1, 9]. Among these typical energetic materials, $H M X$ is one of the most commonly used traditional explosives in propellants and explosives, it was first discovered as a by-product of synthesis of RDX in 1930 [8] and its molecular structure is similar to RDX, with the characteristics of high energy density, high melting point and high explosive performance [1, 8-10]. However, ideal energetic materials should have the advantages of good detonation performance as well as the low thermal and impact sensitivity $[1,11]$. It is difficult to meet the requirements of insensitive high density energetic materials (IHDEMs) $[12,13]$ for HMX due to its moderate sensitivity $[8,11]$, so the effective methods to reduce the sensitivity of HMX without significant energy reduction has aroused extensive attention in the academic circle $[14,15]$.

Cocrystallization, which is the result of intermolecular interactions between two or more neutral molecules such as hydrogen bonds, $\pi$-stacking, and van der Waals forces $[16,17]$. Studies show that the sensitivity of HMX with inert molecules cocrystal is usually lower than that of pure $\mathrm{HMX}[8,18]$ and it is a promising method to solve this problem [16]. N-methyl-2-pyrrolidone (NMP) with a carbonyl group, it is a unique functional group and it is solvent molecule $[4,18,19]$. It is reported that the cocrystallization of HMX and NMP is helpful in reducing the sensitivity of the explosive [18, 20]. In 1985, Haller and Rheingold et al. [21] prepared the HMX/NMP cocrystal by cooling crystallization for the first time and obtained the lattice parameters of the structure. In 2013, Lin and Zhu et al. [22] prepared the HMX/NMP cocrystal by solution evaporation method and investigated host-guest interactions of the structure by using the firstprinciples calculations. But as far as we know, the calculations of electronic properties for the HMX/NMP 
cocrystal by Lin et al. are inaccurate, as can be seen from the band structure and state density diagrams (the parts above the Fermi level are missing). In addition, for cocrystal, intermolecular interactions are the key to the formation of cocrystal structure and are mainly contributed by the intermolecular hydrogen bond interactions [16]. It is of great significance to analyze the intermolecular interactions which may reduce the sensitivity in cocrystal $[11,23]$. Therefore, combined with the above situation, it is very necessary to re-analyze the electronic properties and intermolecular interactions of the HMX/NMP cocrystal.

In our study, we calculated the band structures and the density of states using the first principles, and focused on analyzing its electronic properties and the possible intermolecular hydrogen bond interactions. The research results of this paper as the complement published in 2013 by Lin et al. [22] and we hope to provide some reference and guidance for the design of HMX/NMP cocrystal in the future.

\section{Computational Methods}

In this work, the first principles calculation of HMX/NMP cocrystal were performed using the CASTEP (Cambridge Sequential Total Energy Package) code [24] based on density functional theory (DFT) $[25,26]$ with GGA [27] in the scheme of Perdew-Burke-Ernzerhof (PBE). The cutoff energy of $380.0 \mathrm{eV}$ for the plane-wave was used and the K-points in the Brillouin zone was set to $1 \times 1 \times 1$ throughout all calculations. The electronic configurations of the ions used for the calculation are $2 s^{2} 2 p^{2}$ of $C, 1 s^{1}$ of $H, 2 s^{2} 2 p^{4}$ of $O$, $2 s^{2} 2 p^{3}$ of $N$. In the calculation, we used the experimental data [21] as the structural parameters for calculation and optimized the atomic positions. The atom coordinates for HMX/NMP cocrystal are shown in Table 1, the values in parentheses correspond to the experimental data. 
Table 1

The atom coordinates of HMX/NMP cocrystal.

\begin{tabular}{|llll|}
\hline Atom & $\mathbf{x}$ & $\mathbf{y}$ & $\mathbf{z}$ \\
\hline C1 & $0.52581(0.52880)$ & $0.08519(0.08190)$ & $0.20758(0.20700)$ \\
\hline C2 & $0.44166(0.44000)$ & $-0.09638(-0.09750)$ & $0.21260(0.21410)$ \\
\hline C3 & $0.33333(0.3333)$ & $-0.20064(-0.19828)$ & $0.41447(0.41667)$ \\
\hline C4 & $0.48111(0.45830)$ & $-0.00582(-0.02660)$ & $0.41856(0.42780)$ \\
\hline C5 & $0.25194(0.21140)$ & $-0.29607(-0.022340)$ & $0.39989(0.40060)$ \\
\hline C6 & $0.33333(0.3333)$ & $-0.02918(-0.05138)$ & $0.41667(0.41667)$ \\
\hline C7 & $0.27004(0.21500)$ & $-0.11211(-0.15320)$ & $0.44417(0.40500)$ \\
\hline N1 & $0.35910(0.36540)$ & $-0.01534(-0.01110)$ & $0.19921(0.19080)$ \\
\hline N2 & $0.44371(0.44620)$ & $-0.00832(-0.00960)$ & $0.20665(0.20210)$ \\
\hline N3 & $0.53699(0.52550)$ & $0.13598(0.12820)$ & $0.24664(0.24460)$ \\
N4 & $0.54067(0.53460)$ & $0.22123(0.21610)$ & $0.24504(0.24130)$ \\
N5 & $0.30431(0.30500)$ & $-0.17189(-0.13180)$ & $0.45290(0.41460)$ \\
01 & $0.29407(0.29510)$ & $-0.09249(-0.08640)$ & $0.18855(0.18960)$ \\
O2 & $0.35440(0.37260)$ & $0.05602(0.06470)$ & $0.20281(0.18310)$ \\
03 & $0.54689(0.53860)$ & $0.26098(0.25650)$ & $0.27910(0.27390)$ \\
04 & $0.53860(0.53790)$ & $0.25234(0.24520)$ & $0.20968(0.20520)$ \\
05 & $0.33333(0.3333)$ & $0.04347(0.01692)$ & $0.41667(0.41667)$ \\
\hline & & &
\end{tabular}

\section{Results And Discussion}

\subsection{Crystal structures}

The selected bond lengths in HMX/NMP cocrystal along with the corresponding experimental data [20] are shown in Table 2. It can be seen that the bond lengths compare well with experimental values which indicates that our results agree well with the experimental values. The calculated structure of the HMX/NMP cocrystal model viewed along the $x$ axis is shown in Fig. 1. As seen from Fig. 1, HMX and NMP molecules are arranged in a staggered manner in the structure, which makes the whole crystal structure compact and contributes to the stability of the crystal structure [28-31]. The HMX/NMP cocrystal is a trigonal structure with the space group $R^{\prime} 3 c$ and the lattice parameters are $a=b=16.607 \AA$ and $\mathrm{c}=31.506 \AA$ [21], the molecular formula is $\mathrm{C}_{9} \mathrm{H}_{17} \mathrm{~N}_{9} \mathrm{O}_{9}$. Figure 2 shows more detailed structural information of the HMX/NMP cocrystal. The arrangement of HMX and NMP molecules viewed along the 
$z$ axis is shown in Fig. 2 (a) [21], it can be seen that these two molecules are in a disordered arrangement in the cocrystal. Figure 2 (b) and (c) show the HMX molecule and NMP molecule with atom numbering. For HMX molecule $\left(\mathrm{C}_{4} \mathrm{H}_{8} \mathrm{~N}_{8} \mathrm{O}_{8}\right)$, there are three clearly defined structural motifs in HMX cocrystals, namely, chair - chair/layered, chair - chair/pocket, and chair/layered [8]. As can be seen in Fig. 2 (b), the HMX molecule shows the chair-chair ring conformation $[19,20]$ in HMX/NMP cocrystal, and there are four nitro groups on the same side of the $\mathrm{C}_{4} \mathrm{~N}_{4}$ ring [32].

Table 2

Selected bond lengths along with experimental data in HMX/NMP cocrystal.

\begin{tabular}{|llll|}
\hline Bond & Length $(\AA)$ & Bond & Length $(\AA)$ \\
\hline C1-N2 & $1.468(1.444)$ & N4-O3 & $1.237(1.221)$ \\
\hline C1-N3 & $1.450(1.441)$ & N4-O4 & $1.236(1.237)$ \\
\hline C2-N2 & $1.458(1.464)$ & N1-O2 & $1.231(1.226)$ \\
\hline C2-N3 & $1.447(1.455)$ & N3-N4 & $1.387(1.373)$ \\
\hline N1-O1 & $1.240(1.222)$ & N1-N2 & $1.370(1.370)$ \\
\hline
\end{tabular}

\subsection{Electronic properties}

The calculated energy band structures along the high symmetry direction of the Brillouin zone is shown in Fig. 3, the vertical dashed line at $0 \mathrm{eV}$ is Fermi level. It can be seen that the valence band minimum (VBM) and the conduction band maximum (CBM) are both located at $\mathrm{G}$ point, this indicates that the HMX/NMP cocrystal shows direct bandgap behavior, the value of direct bandgap is $0.958 \mathrm{eV}$. In addition, the valence bands and conduction bands of band structures are quite flat along different symmetry directions in the Brillouin zone, which suggests that it is limited for overlap between orbitals on neighboring molecule, and the interaction between HMX and NMP molecules is rather weak in the cocrystal [33,34].

In order to get more information about the electronic properties of the HMX/NMP cocrystal, we calculated the DOS (density of states) as shown in Fig. 4. Combining with TDOS (total density of states) and PDOS (partial density of states), the main characteristics of DOS can be summarized as follows. (1) These peaks are sharp and localized from PDOS, this indicates that the interactions in the cocrystal are weak, these peaks are associated with previous flat band structure (Fig. 3). (2) The density of states near Fermi level originates predominantly from $\mathrm{N}-2 \mathrm{p}, \mathrm{C}-2 \mathrm{~s}, \mathrm{C}-2 \mathrm{p}$ and $\mathrm{H}-1 \mathrm{~s}$ states, the density of states of $\mathrm{C}-2 \mathrm{~s}$ and $\mathrm{O}-$ $2 p$ orbits are approximately zero at Fermi level. (3) At the bottom of conduction band region, the peaks are dominated by $\mathrm{N}-2 \mathrm{p}$ and $\mathrm{0}-2 \mathrm{p}$ orbits. At the top of valence band region, the peaks are mainly contributed by $\mathrm{N}-2 \mathrm{p}$ and $\mathrm{H}-1 \mathrm{~s}$ orbits. (4) The density of states in the energy range of $-15 \mathrm{eV}$ to $-14 \mathrm{eV}$ originates predominantly from $\mathrm{N}-2 p$ and $\mathrm{C}-2 \mathrm{~s}$ states, their peaks occur around $-14.5 \mathrm{eV}$, this means that strong hybridization between the $\mathrm{N}-2 \mathrm{p}$ and $\mathrm{C}-2 \mathrm{~s}$ states. Meanwhile, the PDOS shows that there is a hybridization between $\mathrm{N}-2 \mathrm{p}$ and $\mathrm{0}-2 \mathrm{p}$ at $-2 \mathrm{eV}$. (5) The conduction bands around $3 \mathrm{eV}$ are mainly composed of the hybridization interactions between $\mathrm{C}-2 \mathrm{p}$ and $\mathrm{H}-1 \mathrm{~s}$. (6) There is a hybridization between 
$\mathrm{O}-2 \mathrm{p}$ and $\mathrm{H}-1 \mathrm{~s}$ states in the energy range of $-3 \mathrm{eV}$ to $-1 \mathrm{eV}$ and $2 \mathrm{eV}$ to $3 \mathrm{eV}$. This indicates that there is interaction between the $\mathrm{O}$ atom and $\mathrm{H}$ atom. Meanwhile, it is worth noting that the density of states from 0-2p is mainly located below Fermi energy ( $3 \mathrm{eV}$ to $-1 \mathrm{eV}$ ) which indicates that charge partially transferred from the weak $\mathrm{H}$ atoms to the strong $\mathrm{O}$ atoms [21, 33].

\subsection{Intermolecular interactions}

Intermolecular interactions are the primary drive forces for the formation of cocrystal and they contribute to the stability of the crystal structure $[35,36]$. The hydrogen bonding is considered as one of the intermolecular interactions in numerous studies [37-41] and they are usually expressed in terms of X-H... $\mathrm{Y}$ [42-44]. For HMX/NMP cocrystal, the intermolecular hydrogen bond interactions between HMX molecule and NMP molecule are the main forces for the formation of HMX/NMP cocrystal, especially the hydrogen bond interaction between nitro group in HMX and neighboring hydrogen $[35,36]$. In most of the examples of hydrogen bonds, the distance between $\mathrm{H}$ and $\mathrm{Y}$ atoms is less than the sum of their van der Waals radii $[37,38,45]$. Therefore, it can be preliminarily inferred the existence of hydrogen bond between $\mathrm{O}$ and $\mathrm{H}$ atoms when their distance is less than the sum of their van der Waals [45] for HMX/NMP cocrystal $[8,33,38,46]$. In this study, we used $1.20 \AA$ and $1.52 \AA$ as the van der Waals radii of $\mathrm{H}$ and $\mathrm{O}$ [45], respectively.

Based on this method, we find the possible existence of hydrogen bonds between 05 and $\mathrm{H} 16,05$ and $\mathrm{H} 17, \mathrm{O} 6$ and $\mathrm{H} 19, \mathrm{O} 6$ and $\mathrm{H} 25, \mathrm{O} 7$ and $\mathrm{H} 19, \mathrm{O} 8$ and $\mathrm{H} 24, \mathrm{O} 9$ and $\mathrm{H} 20,09$ and $\mathrm{H} 24,09$ and $\mathrm{H} 26,010$ and $\mathrm{H} 21,011$ and $\mathrm{H} 21$. The possible hydrogen bonds between HMX and NMP moleculars are shown in Fig. 5. In the Fig. 5 (a), the hydrogen bonds are indicated by the dotted lines, the HMX and NMP moleculars connected to each other by these possible hydrogen bonds. The $\mathrm{H}$ atoms of the methylene groups in $\mathrm{HMX}$ or the $\mathrm{H}$ atoms in the NMP molecular serve as proton donors, and the $\mathrm{O}$ atoms of the nitro groups in $\mathrm{HMX}$ or the $\mathrm{O}$ atoms in the NMP molecular serve as proton acceptors. We can see that there are three different intermolecular interactions between HMX and NMP moleculars in HMX/NMP cocrystal from Fig. 5 (b). These three types of intermolecular interactions play important roles in stabilizing cocrystal, combined with other weak interactions such as C...N interactions, finally form the structure. The distances and angles of possible hydrogen bonds found in cocrystal have been listed in Table 3, the labeled atoms are shown in Fig. 5 (b). In these possible hydrogen bonds, the shortest contact is $\mathrm{C} 11 \mathrm{H} 24$...08 with 2.091 $\AA$ and the longest one is $\mathrm{C} 8 \mathrm{H} 19 . . .06$ with $2.611 \AA$. In addition, their bond angles are above $110^{\circ}$ except the $\mathrm{C} 10 \mathrm{H} 20 . . .09$ and $\mathrm{C} 11 \mathrm{H} 26 . . .09$. It is reported in previous literature $[37,38]$ that the hydrogen bond angle should preferably be above $110^{\circ}$, the bond angles of these bonds are basically consistent with this conclusion. HMX and NMP molecules are alternately arranged in the cocrystal structure and connected by these hydrogen bonds, which increase the stability of the structure and safety of the cocrystal explosive. And this is one of the reasons for the decreased sensitivity of this cocrystal explosives [28-31, 47-49]. 
Table 3

The possible intermolecular hydrogen bonds in the HMX/NMP cocrystal.

\begin{tabular}{|c|c|c|c|c|}
\hline$X-\mathrm{H}_{\ldots} . . \mathrm{Y}$ & $\mathrm{X}-\mathrm{H}(\AA)$ & H...Y $(\AA ̊)$ & $X \ldots . . .(\AA)$ & $\angle \mathrm{X}-\mathrm{H} . . . \mathrm{Y}\left({ }^{\circ}\right)$ \\
\hline C1-H16...O5 & 1.094 & 2.224 & 2.948 & 121.564 \\
\hline C2-H17...O5 & 1.088 & 2.282 & 2.866 & 130.947 \\
\hline C8-H19...O7 & 2.128 & 2.471 & 4.368 & 143.408 \\
\hline C8-H19...O6 & 2.128 & 2.611 & 4.690 & 163.417 \\
\hline C9-H25...O6 & 3.800 & 2.499 & 4.700 & 134.436 \\
\hline C10-H20...09 & 1.081 & 2.356 & 2.716 & 89.134 \\
\hline $\mathrm{C} 10-\mathrm{H} 21 \ldots 010$ & 1.091 & 2.449 & 3.336 & 137.529 \\
\hline $\mathrm{C} 10-\mathrm{H} 21 \ldots 011$ & 1.091 & 2.379 & 3.314 & 142.673 \\
\hline $\mathrm{C} 11-\mathrm{H} 24 \ldots 08$ & 2.125 & 2.091 & 3.494 & 111.969 \\
\hline C11-H24...O9 & 2.125 & 2.350 & 4.195 & 139.179 \\
\hline $\mathrm{C} 11-\mathrm{H} 26 \ldots .09$ & 3.800 & 2.216 & 4.195 & 84.026 \\
\hline
\end{tabular}

The electronic overlap in PDOS is generally interpreted as one of the evidence of the interaction for nonbond atoms $[32,33,46]$. In order to further study these interactions, we present the PDOS of the correlative $\mathrm{O}$ and $\mathrm{H}$ atoms $(\mathrm{O} 5, \mathrm{O} 6, \mathrm{O} 7, \mathrm{O} 8, \mathrm{O}, \mathrm{O} 10, \mathrm{O} 11, \mathrm{H} 16, \mathrm{H} 17, \mathrm{H} 19, \mathrm{H} 2 \mathrm{O}, \mathrm{H} 21, \mathrm{H} 24, \mathrm{H} 25, \mathrm{H} 26)$ in the HMX/NMP cocrystal as shown in Fig. 6. From Fig. 6 (a), it can be observed that resonance is found between 05 and $\mathrm{H} 16$ from $-7 \mathrm{eV}$ to $-5 \mathrm{eV}$. The resonance is also found between 05 and $\mathrm{H} 17$ from $-6 \mathrm{eV}$ to $-5 \mathrm{eV}$, especially their peaks appear at the same level with $-5.5 \mathrm{eV}$. This indicates that hydrogen bond interactions occur between 05 and H16, 05 and H17. Similarly, in the Fig. 6 (b), there are hydrogen bond interactions between $\mathrm{O} 6$ and $\mathrm{H} 119$ states in the energy range of $-10 \mathrm{eV}$ to $-9 \mathrm{eV}$. And in the energy range of $-4 \mathrm{eV}$ to $-2 \mathrm{eV}$, there are hydrogen bond interactions between 06 and $\mathrm{H} 25$ states. As Fig. 6 (c) - (e) show, the hydrogen bond interactions also occur between $\mathrm{O} 9$ and $\mathrm{H} 20,09$ and $\mathrm{H} 26,07$ and $\mathrm{H} 19,08$ and $\mathrm{H} 24$. This is basically consistent with the previous results obtained by the distance method to determine the existence of hydrogen bond interactions. In addition, these hydrogen bond interactions can be divided into two types: $\mathrm{C}-\mathrm{H} . . . \mathrm{O}-\mathrm{C}$ and $\mathrm{C}-\mathrm{H} . . . \mathrm{O}-\mathrm{N}$ hydrogen bonds. The hydrogen bond interactions between 05-2p in NMP molecules and $\mathrm{H}-1$ s states $(\mathrm{H} 16$ and $\mathrm{H} 17)$ belong to $\mathrm{C}-\mathrm{H} . . . \mathrm{O}-\mathrm{C}$ hydrogen bonds, the other hydrogen bond interactions between other 0-2p (06, 07, 08 and 09) states in $\mathrm{HMX}$ molecules and $\mathrm{H}-1$ s states belong to $\mathrm{C}-\mathrm{H}$... O-N hydrogen bonds. It can be seen form the Fig. 6 that the hydrogen bonds in HMX/NMP crystal mainly comes from the $\mathrm{C}-\mathrm{H}$... O-N hydrogen bonds. Therefore, the strength of the hydrogen bond interactions for $\mathrm{C}-\mathrm{H} . . . \mathrm{O}-\mathrm{N}$ is higher than $\mathrm{C}-\mathrm{H} . . . \mathrm{O}-\mathrm{C}$ hydrogen bonds in the HMX/NMP cocrystal explosive.

\section{Conclusions}


In summary, based on the density functional theory, we have studied the electronic properties and intermolecular interactions by analyzing its band structure and the density of states. The main results and conclusions were summarized as follows in this study: 1 . There is a direct band gap in the HMX/NMP cocrystal. 2. The interaction between HMX and NMP molecules is rather weak due to its bands being quite flat and its peaks from PDOS are localized. 3. There are hybridization interactions between $\mathrm{N}-2 \mathrm{p}$ and $\mathrm{0}-2 \mathrm{p}$ states, $\mathrm{O}-2 \mathrm{p}$ and $\mathrm{H}-1$ s states, $\mathrm{N}-2 \mathrm{p}$ and $\mathrm{C}-2 \mathrm{~s}$ states, $\mathrm{C}-2 \mathrm{p}$ and $\mathrm{H}-1 \mathrm{~s}$. 4 . There is interaction between the $\mathrm{O}$ atom and $\mathrm{H}$ atom, the parts of charge transform from $\mathrm{H}$ to $\mathrm{O}$ atoms. 5. Three types of intermolecular interactions play important roles in stabilizing the HMX/NMP cocrystal, and the C$\mathrm{H} . . . \mathrm{O}$ hydrogen bond interaction is the key role. 6 . The arrangement of HMX and NMP molecules in the structure and the hydrogen bonds between them are the main reasons for the decrease of the sensitivity of the cocrystal. 7. The strength of the hydrogen bond interactions for $\mathrm{C}-\mathrm{H} . . . \mathrm{O}-\mathrm{N}$ is higher than that of $\mathrm{C}$ $\mathrm{H}$... O-C hydrogen bond interactions.

\section{Declarations}

\section{Funding}

This project was supported by the Fund of the Key Laboratory of National Defense Science and Technology (Grant No. 6142A03182008).

\section{Conflicts of interest/Competing interests}

All authors declare that we have no known competing financial interests or personal relationships that could have appeared to influence the work reported in this manuscript.

\section{Availability of data and material}

The data sets supporting the results of this work are included within the article, the other datasets generated during the current study are available from the corresponding author on reasonable request.

\section{Code availability}

Not applicable

\section{Authors' contributions}

Yi-Hua Du: Writing - original draft, Formal analysis, Investigation, Methodology, Software

Fu-Sheng Liu: Data curation, Methodology, Writing - review \& editing

Qi-Jun Liu: Conceptualization, Project administration, Resources, Supervision, Writing - review \& editing Bin Tang: Methodology, Software, Writing - review \& editing

Mi Zhong: Data curation, Writing - review \& editing, Visualization 
Ming-Jian Zhang: Investigation, Methodology, Writing - review \& editing

\section{Ethics approval}

Not applicable

\section{Consent to participate}

Not applicable

\section{Consent for publication}

Not applicable

\section{Acknowledgments}

This work was supported by the Fund of the Key Laboratory of National Defense Science and Technology (Grant No. 6142A03182008).

\section{References}

1. Badgujar DM, Talawar MB, Asthana SN, Mahulikar PP (2008) J Hazard Mater 151:289

2. Fried LE, Manaa MR, Pagoria PF, Simpson RL (2001) Annu Rev Mater Res 31:291

3. Urbanski T (1965) Chemistry and Technology of Explosives. Volume I. Jamchemsoc 87:3031

4. Yang ZW, Zeng Q, Zhou XQ, Zhang Q, Nie FD, Huang H, Li HZ (2014) Rsc Advances 4:65121

5. Wang ZS (2006) An Introduction to Energetic Materials. Heilongjiang Harbin Institute of Technology Press, Harbin

6. Guo CY, Zhang HB, Wang XC, Xu JJ, Liu Y, Liu XF, Huang H, Sun J (2013) J Mol Struct 1048:267

7. Pagoria PF, Lee GS, Mitchell AR, Schmidt RD (2002) Thermochim Acta 384:187

8. Landenberger KB, Matzger AJ (2012) Cryst Growth Des 12:3603

9. Lyncha JC, Brannonb JM, Delfino JJ (2002) Chemosphere 47:725

10. Lin H, Chen JF, Zhu SG, Li HZ, Huang Y (2017) J Energ Mater 35:95

11. Lin H, Zhu SG, Zhang L, Peng XH, Chen PY, Li HZ (2013) Int J Quantum Chem 113:1591

12. Klapötke TM, Sabaté CM (2008) Chem Mater 20:3629

13. An CW, Li FS, Song XL, Wang Y, Guo XD (2009) Propellants Explos. Pyrotech 34:400

14. Shen JP, Duan X, Luo QP, Zhou Y, Bao QL, Ma YJ, Pei CH (2011) Cryst Growth Des 11:1759

15. Agrawal JP (1998) Progress in Energy \& Combustion ence 24:1

16. Bolton O, Matzger AJ (2011) Angew Chem 123:9122

17. Chieng N, Hubert M, Saville D, Rades T, Aaltonen J (2009) Syst Biol 50:367

18. Tian BB, Chen LZ, Zhang CY (2019) Chinese Journal of Energetic Materials 27:883 
19. Jouyban A, Fakhree MAA, Shayanfar A (2010) Journal of Pharmacy Pharmaceutical Sciences 13:524

20. Ou YX (2006) Frying pharmacy. Beijing Institute of Technology Press, Beijing

21. Haller TM, Rheingold AL, Brill TB (1985) Acta Cryst. C41:963

22. Lin H, Zhu SG, Zhang L, Peng XH, Li HZ (2013) J Energ Mater 31:261

23. Hadadzadeh H, Rezvani AR, Abdolmaleki MK, Ghasemi K, Esfandiari H, Daryanavard M (2010) J Chem Crystallogr 40:48

24. Clark JS, Segall MD, Pickard CJ, Hasnip PJ, Probert MIJ, Refson K, Payne MC (2005) Z Kristallogr 220:567

25. Hohenberg P, Kohn W (1964) Phys Rev 136:864

26. Jones RO, Gunnarsson $O$ (1989) Rev Mod Phys 61:689

27. Perdew JP, Burke K, Ernzerhof M (1996) Phys Rev Lett 77:3865

28. Wang YP, Yang ZW, Li HZ, Wang JH, Zhou XQ, Zhang Q (2013) Chinese Journal of Energetic Materials 21:554

29. Wang YP, Yang ZW, Li HZ, Zhou XQ, Zhang Q, Wang JH, Liu YC (2014) Propellants Explos Pyrotech 39:590

30. Bemm U, Östmark H (1998) Acta Cryst. 54:1997

31. Yang ZW, Li HZ, Zhou XQ, Nie FD, Li JS, Huang H (2012) Chinese Journal of Energetic Materials 6:674

32. Chen F, Zhang H, Zhao F, Meng CM, Cheng XL (2010) Sci China Phys Mech Astron 53:1080

33. Chen F, Cheng XL (2011) Int J Quantum Chem 111:4457

34. Ahuja BL, Jain P, Sahariya J, Heda NL, Soni P (2013) J Phys Chem A 117:5685

35. Jetti RKR, Boese R, Thallapally PK, Desiraju GR (2003) Cryst Growth Des 3:1033

36. Naether C, Arad C, Bock H (1997) Acta Cryst. 53:76

37. Arunan E, Desiraju GR, Klein RA, Sadlej J, Scheiner S, Alkorta I, Clary DC, Crabtree RH, Dannenberg JJ, Hobza P, Kjaergaard HG, Legon AC, Mennucci B, Nesbitt DJ (2011) Newsmagazine for IUPAC 83:1619

38. Arunan E, Desiraju GR, Klein RA, Sadlej J, Scheiner S, Alkorta I, Clary DC, Crabtree RH, Dannenberg JJ, Hobza P, Kjaergaard HG, Legon AC, Mennucci B, Nesbitt DJ (2011) Newsmagazine for IUPAC 83:1637

39. Steiner T, Desiraju GR (1998) Chem Commun 8:891

40. Etter MC (1990) Accounts of Chemical Research 23:120

41. Bratoz S (1967) Advances in Quantum Chemistry 3:209

42. Zhang WH (2007) Journal of Ningxia Teacher University 28:84

43. Steiner $T$ (2002) Angew. Chem. Int Ed 41:48

44. Barbiellini B, Shukla A (2002) Phys Rev B 66:235101

45. Bondi A (1964) J Phys Chem 68:441 
46. Chen F, Zhang H, Zhao F, Li QL, Qu JY (2008) J Mol Struct (Thoechem) 864:89

47. Li X, Sun Q, Lin QH, Lu M (2021) Chem Eng J 406:126817

48. Zhang CY, Xue XG, Cao YF, Zhou JH, Zhang AB, Li HZ, Zhou Y, Xu RJ, Gao T (2014) The Royal Society of Chemistry 16:5905

49. Sun T, Xiao JJ, Liu Q, Zhao F, Xiao HM (2014) J Mater Chem A 2:13898

Figures

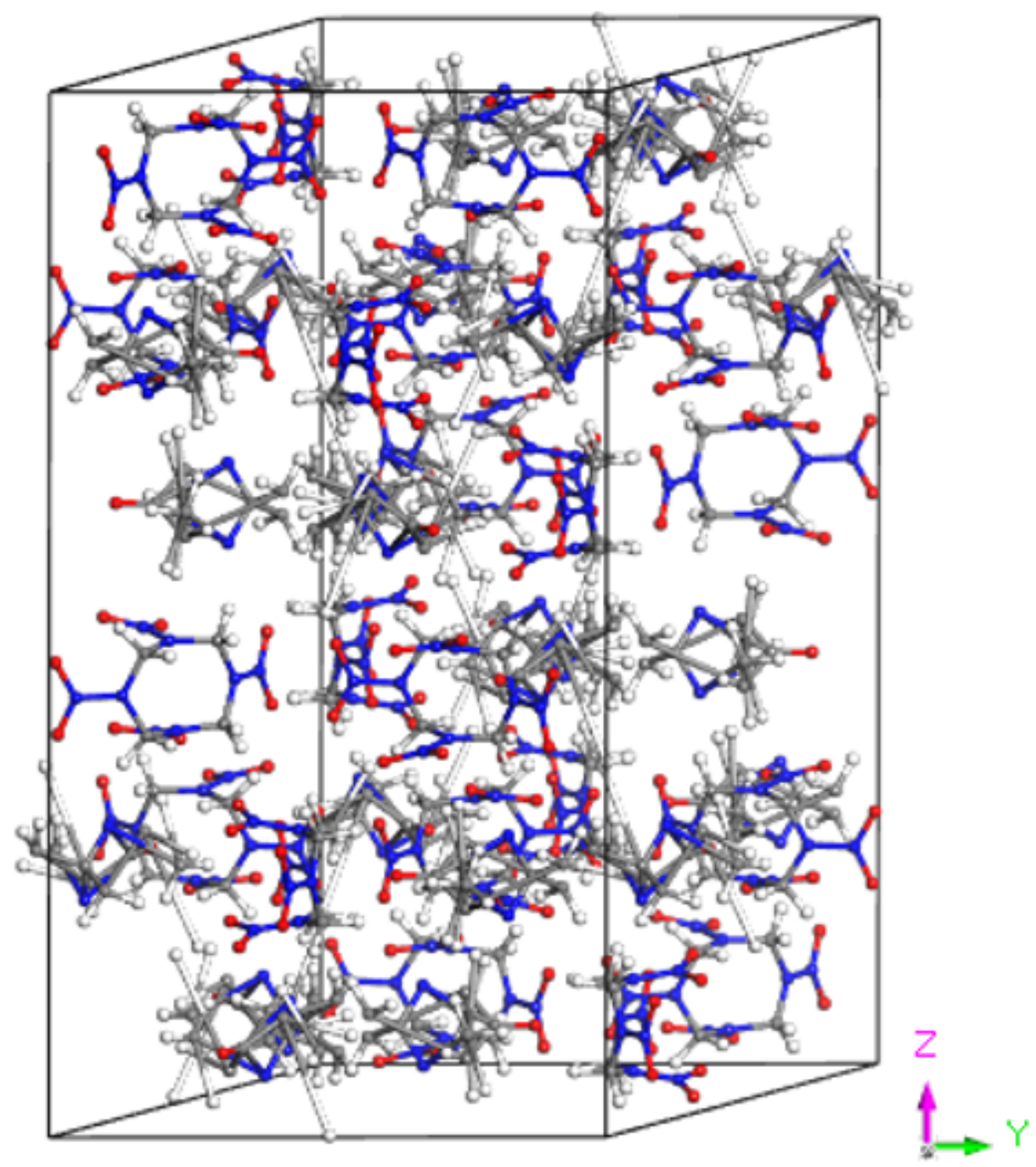

Figure 1

The crystal structures of HMX/NMP cocrystal viewed along the $\mathrm{x}$ axis. 
(a)

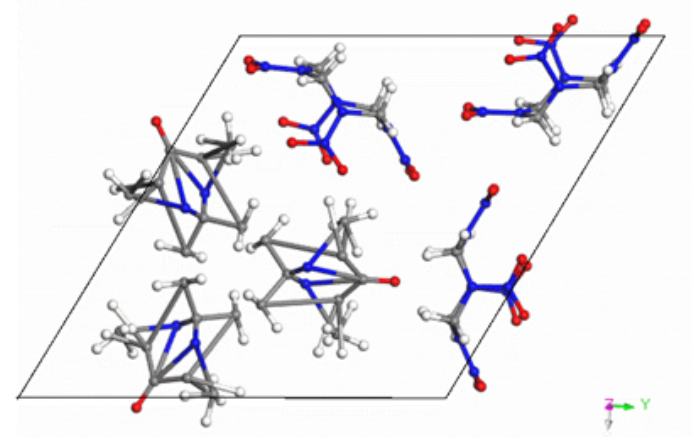

(c)

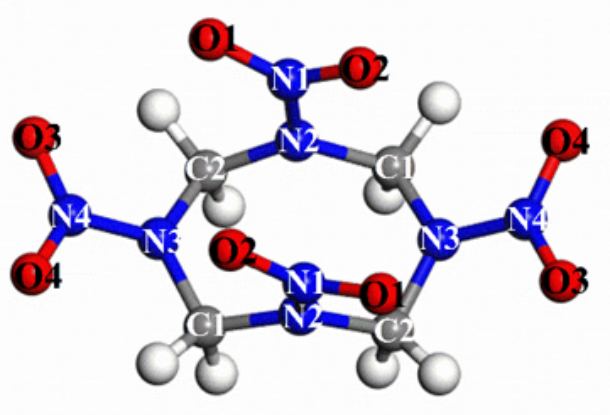

(d)

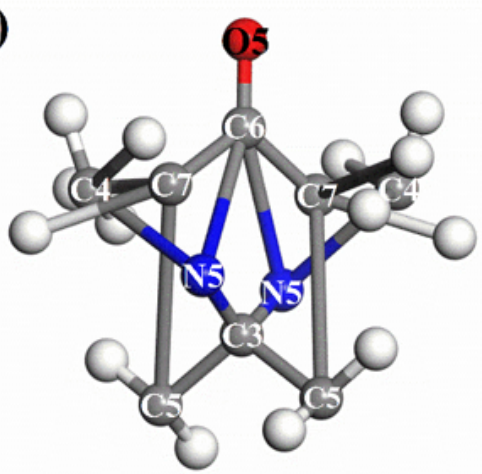

Figure 2

(a) The arrangement of HMX and NMP molecules viewed along the $z$ axis; (b) the molecular structure of HMX; (c) the molecular structure of NMP.

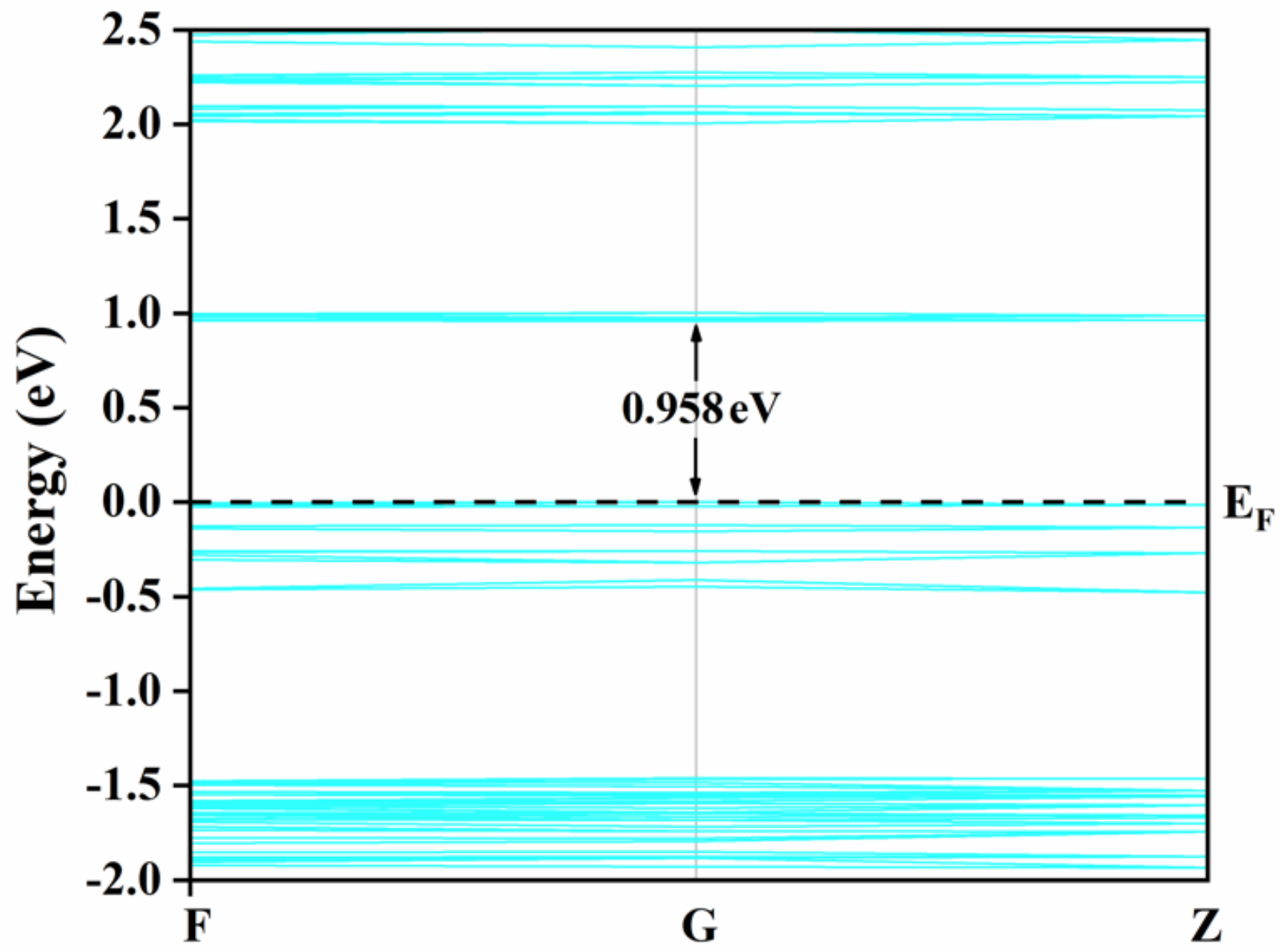

Figure 3

Band structure of HMX/NMP cocrystal. 


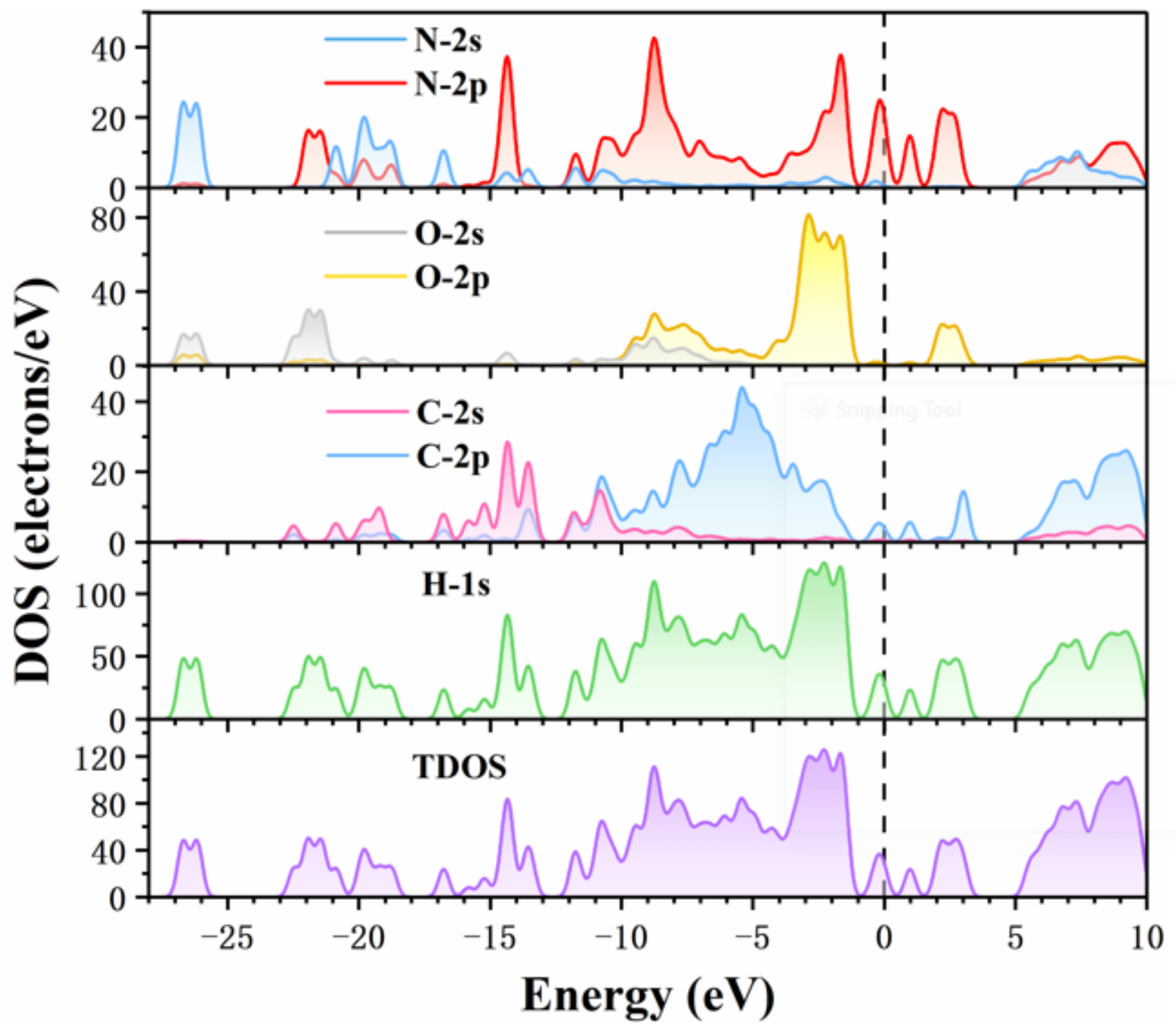

Figure 4

DOS of HMX/NMP cocrystal. 
(a)
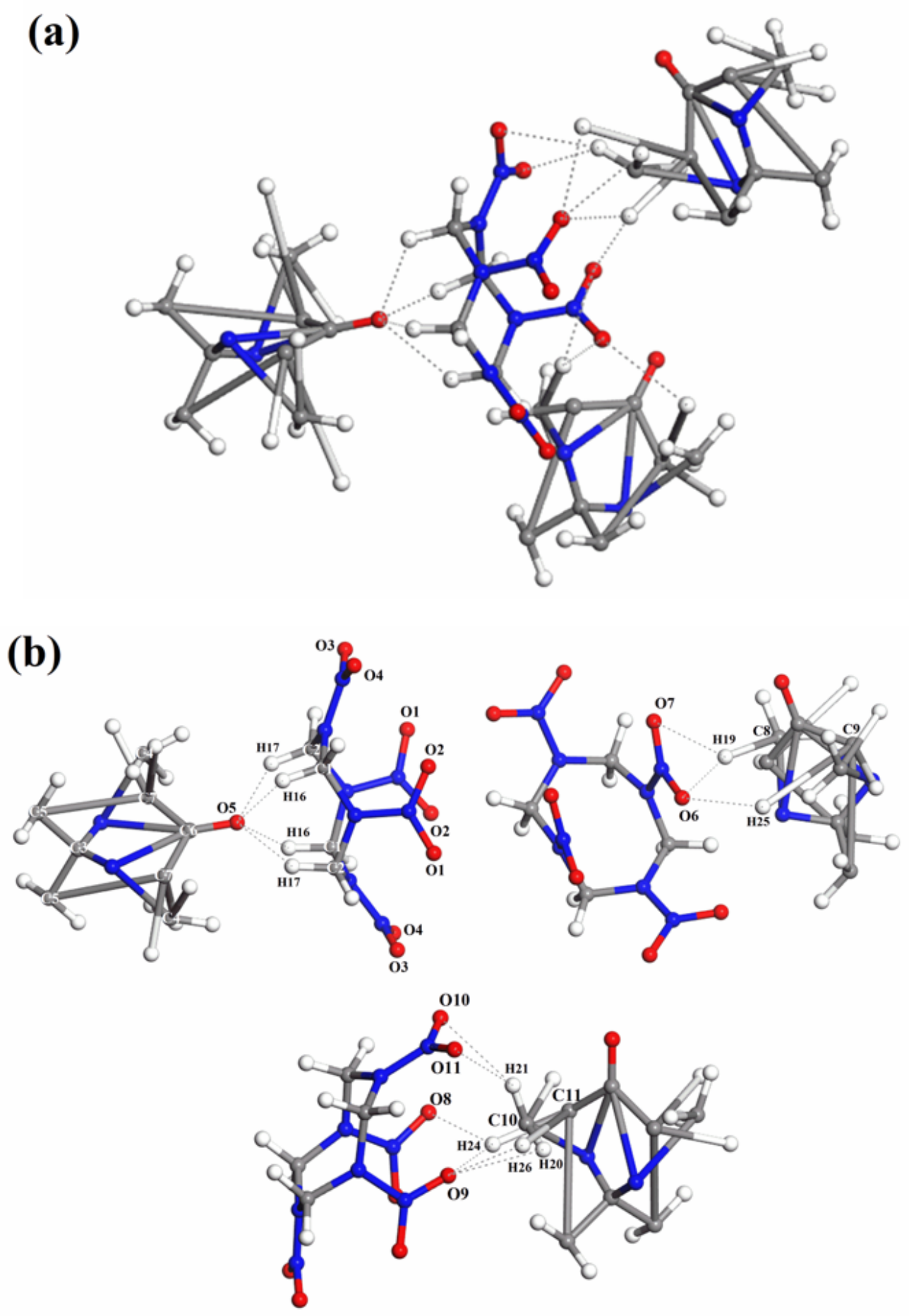

Figure 5

(a) The possible hydrogen bonds between HMX molecule and NMP molecule found in cocrystal; (b) three intermolecular interactions between HMX and NMP in cocrystal (the hydrogen bonds are indicated by the dotted lines). 

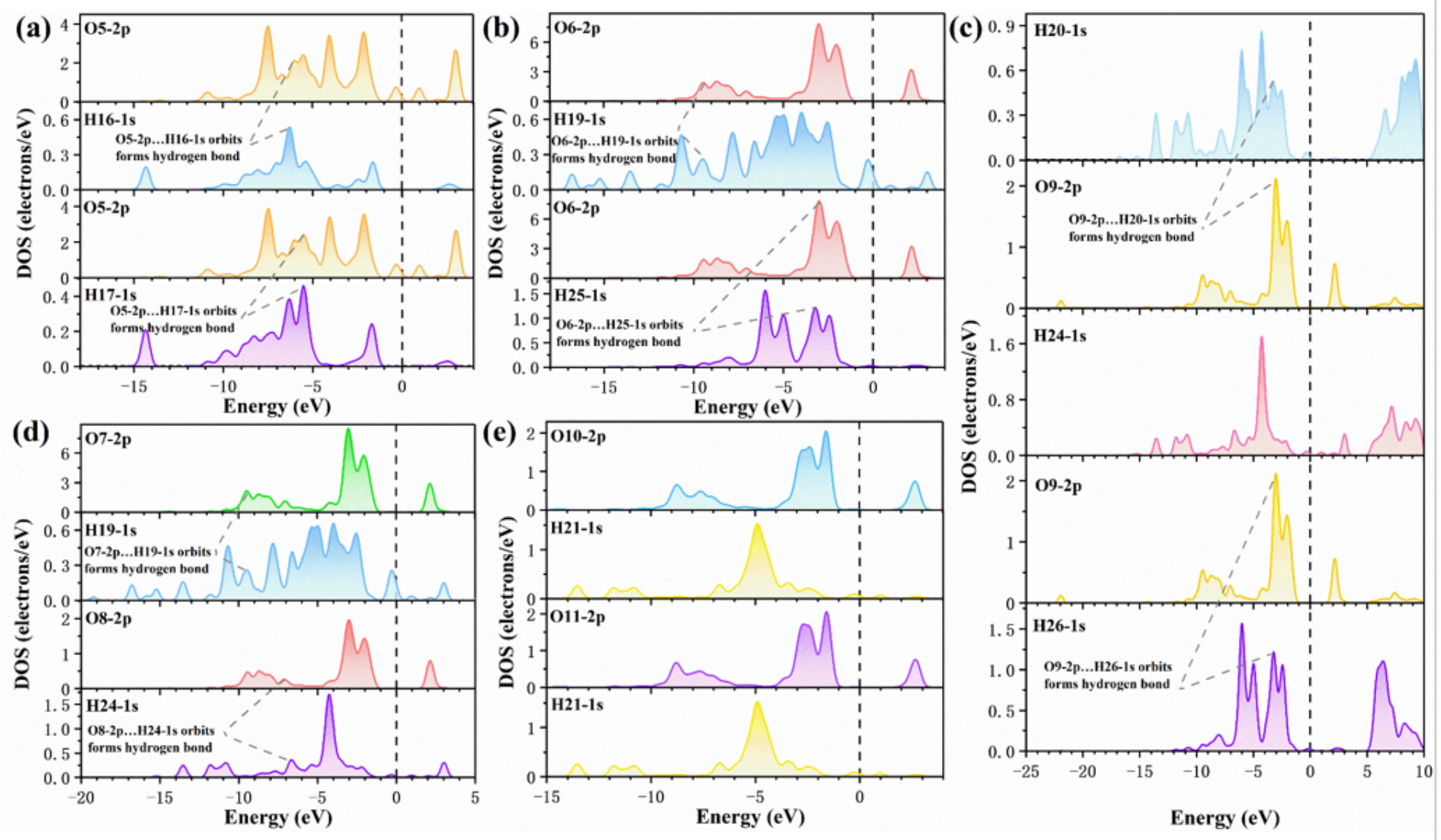

Figure 6

The PDOS of the $\mathrm{O}$ and $\mathrm{H}$ atoms in the HMX/NMP cocrystal: (a) 05 and H16, O5and H17, (b) 06 and H19, $\mathrm{O} 6$ and $\mathrm{H} 25$, (c) 09 and $\mathrm{H} 20$, O9and $\mathrm{H} 24,09$ and $\mathrm{H} 26$ (d) O7and $\mathrm{H} 19$, $\mathrm{O} 8$ and $\mathrm{H} 24$, (e) $\mathrm{O} 10$ and $\mathrm{H} 21,011$ and $\mathrm{H} 21$. 